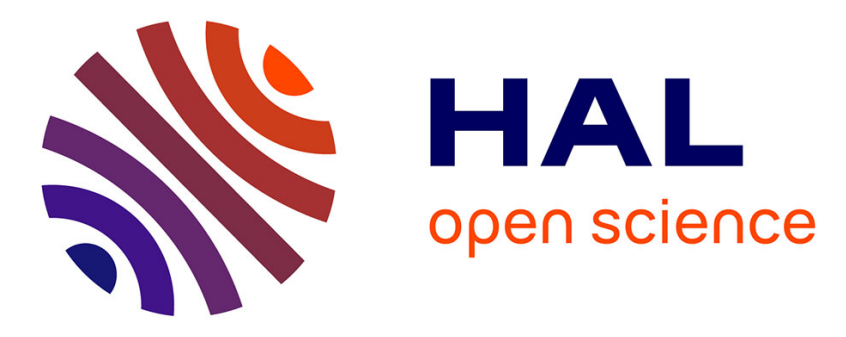

\title{
Sudden Cardiac Arrest: ECG Repolarization After Resuscitation.
}

Nicolas Lellouche, Frederic Sacher, Pierre Jorrot, Alain Cariou, Christian

Spaulding, Amandine Aurore, Xavier Combes, Jerome Fichet, Emmanuel

Teiger, Pierre Jais, et al.

\section{To cite this version:}

Nicolas Lellouche, Frederic Sacher, Pierre Jorrot, Alain Cariou, Christian Spaulding, et al.. Sudden Cardiac Arrest: ECG Repolarization After Resuscitation.. Journal of Cardiovascular Electrophysiology, 2011, 22 (2), pp.131-6. 10.1111/j.1540-8167.2010.01871.x . inserm-00574923

\section{HAL Id: inserm-00574923 https://www.hal.inserm.fr/inserm-00574923}

Submitted on 9 Sep 2011

HAL is a multi-disciplinary open access archive for the deposit and dissemination of scientific research documents, whether they are published or not. The documents may come from teaching and research institutions in France or abroad, or from public or private research centers.
L'archive ouverte pluridisciplinaire HAL, est destinée au dépôt et à la diffusion de documents scientifiques de niveau recherche, publiés ou non, émanant des établissements d'enseignement et de recherche français ou étrangers, des laboratoires publics ou privés. 


\section{Sudden Cardiac Arrest: ECG Repolarization after Resuscitation}

Short title: sudden cardiac arrest and ECG repolarization

Nicolas Lellouche * MD, Frederic Sacher ${ }^{*}$ MD, Pierre Jorrot * MD, Alain Cariou $†$ MD, Christian Spaulding † MD, Amandine Aurore * MD, Xavier Combes * MD, Jerome Fichet $†$ MD, Emmanuel Teiger * MD, Pierre Jais * ${ }^{*}$ MD, Jean-Luc DuboisRandé * MD, Michel Haissaguerre ** MD

* Hôpital Henri Mondor, Assistance Publique Hôpitaux de Paris et INSERM U 841, 51 Avenue du Maréchal de Lattre de Tassigny 94000 CRETEIL

${ }^{* *}$ Hopital Cardiologique du Haut-Leveque, CHU de Bordeaux / Université Bordeaux II, 33604 Pessac CEDEX

† Hôpital Cochin, Assistance Publique Hôpitaux de Paris, 27 rue du Faubourg SaintJacques 75005 PARIS

\section{DISCLOSURES}

None declared

Total word count: 3334

Address for correspondence: Federation de Cardiologie Hopital Henri Mondor 51

Avenue du Marechal de Lattre de Tassigny, 94000 CRETEIL, France

Telephone: +33.1 .49 .81 .43 .50$

Fax: +33.1 .49 .81 .42 .24 .

E-mail: nicolellouche@yahoo.com 


\section{INTRODUCTION}

Out-of-hospital sudden cardiac arrest (OHCA) is a relatively common situation associated with a high mortality rate $(1,2)$. The main cause of OHCA is known to be acute coronary syndrome $(3,4)$. Electrocardiogram $(E C G)$ is the first diagnostic tool that helps in the care of patients with OHCA. However, ECG and particularly repolarization abnormalities are frequent after a cardiac arrest (5) and the prediction of an acute ischemic event from an ECG immediately following cardiac arrest is controversial $(5,6)$. Moreover, early repolarization (ERep) has recently been associated with sudden cardiac death $(7,8)$. The aim of our study was to assess the value of different repolarization abnormality patterns on the first ECG recorded immediately after OHCA in predicting the presence or absence of acute ischemic disease and the ECG evolution in surviving patients.

\section{METHODS}

\section{Patients}

The following patients were eligible: age over 18 years old and having experienced OHCA of presumed cardiac origin with at least one ECG in supra-ventricular rhythm. Exclusion criteria were: cardiac arrest of non-cardiac etiology (i.e. trauma, sepsis, acute respiratory failure. . .); pregnancy, and/or known terminal illness before the occurrence of cardiac arrest. 


\section{Study design}

This was a retrospective two-center and observational study on OHCA occurring between January 2004 and December 2007. These patients were managed in Henri Mondor University Hospital (Creteil, France) and Cochin University Hospital (Paris, France).

\section{Patient management}

In Paris, the management of OHCA involves emergency units based in five hospitals in the city (our two centers are part of these hospitals) and one dispatching center with two physicians. Each emergency unit is equipped with one or more ambulances with resuscitation equipment that are always staffed by one or two physicians trained in emergency medicine. For all patients, cardiopulmonary resuscitation was initiated according to standard procedures. Successfully resuscitated patients were included if the sudden cardiac arrest occurred within one hour of the onset of symptoms in the absence of a clear, non-cardiac cause.

As described in Figure 1, the following diagnostic strategy was applied for every patient: patients who met the criteria were brought directly to the cardiac catheterization laboratory (Cochin or Mondor Hospital). Immediate coronary artery \pm left ventricular angiography was performed according to standard techniques. If a recent coronary artery lesion was found, coronary angioplasty and stent implantation were attempted, unless the infarct-related artery was too small or the operator considered the procedure to be technically impossible. Acute coronary lesion was defined as a recent thrombotic coronary occlusion or irregular lesions suggestive of ruptured plaque (Ambrose type 2). 
If coronary angiogram was normal, a cerebral CT scan was performed for the diagnosis of acute cerebral hemorrhage. If the cerebral CT scan was normal, a thoracic CT scan was performed to eliminate an acute massive pulmonary embolism which could explain the sudden cardiac arrest. Patients were then transported to the medical intensive care unit.

\section{ECG Analysis}

ECG was recorded immediately after out-of-hospital sudden cardiac arrest for all patients using a standard digital recorder with 12 simultaneous leads at a paper speed of $25 \mathrm{~mm} / \mathrm{s}$ once supra-ventricular rhythm was stable. Two different experts, blinded to the coronary angiogram results and the follow-up, analyzed all ECGs manually. Our study population was divided into 4 groups according to the repolarization abnormalities noted on the first ECG following successful cardiac resuscitation (Figure 2):

Group 1: No ST segment elevation nor ERep

Group 2: ST segment elevation without ERep

Group 3: ST segment elevation and ERep

Group 4: ERep only

ST segment elevation was defined as an elevation $40 \mathrm{~ms}$ after the $\mathrm{J}$ point of at least $1 \mathrm{~mm}$ in 2 consecutive limb leads and/or $2 \mathrm{~mm}$ in two consecutive precordial leads (12).

ERep was defined as an elevation of the QRS-ST junction (J point) in at least two leads. The amplitude of J-point elevation had to be at least $1 \mathrm{~mm}$ at $10 \mathrm{~mm} / \mathrm{mV}$ scale $(0.1 \mathrm{mV})$ above the baseline level $(9,10)$, either as QRS slurring (a smooth transition from the QRS segment to the ST segment) or notching (a positive J deflection 
inscribed on the S wave) in the inferior lead (II, III, and aVF), lateral lead (I, aVL, and $V_{4}$ to $\left.V_{6}\right)$, or both. The anterior precordial leads $\left(V_{1}\right.$ to $\left.V_{3}\right)$ were excluded from the analysis to avoid the inclusion of patients with right ventricular dysplasia or Brugada syndrome (11).

\section{Follow-Up}

During the hospital stay, major adverse events, including death from any cause, recurrent cardiac arrest, early reocclusion of the infarct-related artery, early reintervention, and stroke, were recorded. Left ventricular ejection fraction (LVEF) was evaluated by echocardiography within the first days after $\mathrm{PCl}$ in all patients using the Simpson method. Patients' neurological recovery and overall performance were estimated at discharge according to current available scales (13). Briefly, cerebral performance was graded from 1 (good cerebral performance, conscious, alert, able to work and lead a normal life despite possible minor psychological or neurological deficits) to 4 (coma, vegetative state, not conscious, no verbal or psychological interactions with environment) according to Glasgow-Pittsburgh cerebral performance categories (14). Clinical follow-up was obtained in all survivors with a minimum of 3 months after hospital discharge, including evaluation of hemodynamics and clinical data.

Patients with ischemic cardiomyopathy were routinely followed by a cardiologist every 6 months. Patients without structural heart disease or with no acute cause for the cardiac arrest received an implantable cardioverter defibrillator.

For patients who survived, all the ECGs recorded during a follow-up of at least one month after cardiac arrest were analyzed. The presence of ERep during the follow-up was noted according to the previously described criteria. Moreover, for survival patients with unknown initial diagnosis, complementary cardiac exploration was 
performed, including transthoracic echocardiography, stress test, MRI or an electrophysiological study if necessary.

The study was approved by an institutional review committee and the subjects who survived gave informed consent.

\section{Statistical Analysis}

Continuous variables were expressed as mean \pm standard deviation (SD), and statistical differences were assessed using the unpaired Student $t$ test or MannWhitney $U$ test if necessary. Analysis of variance (ANOVA) was used to compare continuous variables in the 4 groups, each representative of one repolarization abnormality pattern following cardiac arrest. Categorical variables, expressed as numbers or percentages, were compared with the chi-square test or Fisher's exact test. A univariate analysis of variables was performed. All tests were 2-tailed, and a $p$ value $<.05$ was considered statistically significant.

\section{RESULTS}

\section{Population Characteristics}

Two hundred and twenty-five patients were included in this study. Overall population characteristics are given in Table 1. Mean age was 59 years old and $79 \%$ of our population was male. Hypertension and a preexistent coronary disease were present in $37 \%$ and $23 \%$ of patients respectively. 
Fifty-four percent of the cardiac arrest cases were secondary to acute myocardial ischemia. Acute cerebral event was the underlying cause of the cardiac arrest in $3 \%$ of cases, pulmonary embolism in $3 \%$ and no acute underlying cause was identified in $39 \%$ of the patients. Primary recorded rhythm was ventricular fibrillation (VF) in $68 \%$, asystole in $28 \%$ and pulseless electrical activity in $4 \%$ of cases. Patterns 1, 2, 3, 4 as previously described were observed in 50\% (112 patients), 33\% (74 patients), $8 \%$ (19 patients) and $9 \%$ (20 patients) of our population respectively on the first ECG following cardiac resuscitation.

Our population was then divided into 4 groups according to their repolarization pattern.

\section{Patient characteristics according to repolarization pattern}

As shown in Table 2, patients with ERep (groups 3 and 4) were significantly younger than other patients. Patients with isolated ST segment elevation (pattern 2) exhibited a higher prevalence of VF as primary rhythm following cardiac arrest compared to the other groups.

Moreover, patients with isolated ST segment elevation were more likely (82\%) to have an acute coronary lesion explaining their OHCA, whereas patients with ERep only were more likely to have a non-ischemic cause of death $(85 \%), p<0.0001$. Sensibility and specificity of pattern 2 in predicting acute coronary lesion was $50 \%$ and $88 \%$ respectively. Positive and negative predictive values were $82 \%$ and $60 \%$ respectively.

Pattern 4 had sensitivity, specificity, positive and negative predictive value of $16 \%$, $98 \%, 85 \%$ and $58 \%$ respectively in predicting acutely a non-ischemic event. 
Finally, patients with pattern 4 had a significantly higher LVEF (56 $\pm 10 \%)$ following OHCA compared to the other groups $(42 \pm 16 \%$ for pattern $1,44 \pm 15 \%$ for pattern 2 , $46 \pm 11 \%$ for pattern $3 ; p=0.02$ ).

\section{Patient characteristics according to the presence or absence of an acute coronary lesion (Table 3)}

In our population, 121 patients had a significant acute coronary lesion to account for OHCA whereas 104 patients did not. Patients with acute coronary lesion responsible for OHCA had a significantly higher rate of ventricular fibrillation $(\mathrm{p}=0.003)$ and a lower rate of asystole $(p=0.003)$ compared to patients without acute coronary lesion. Regarding repolarization abnormalities, these patients exhibited a higher rate of pattern 2 and a significantly lower rate of patterns 1 and 4 compared to other patients without acute coronary lesion. Finally, LVEF following cardiac arrest was similar in both groups.

\section{Characteristics of survival patients and follow-up}

In our population of 225 patients, 65 patients (29\%) survived after the OHCA episode and were followed as previously described.

As shown in table 4 , survival patients were significantly younger $(p=0.001)$, with a lower prevalence of diabetes $(\mathrm{p}=0.002)$. Moreover, ventricular fibrillation was more common $(p<0.0001)$ as the primary recorded rhythm after resuscitation and the rate of asystole was lower $(p<0.0001)$ compared to non-survival patients. 
As mentioned in Table 4, no etiology was found during initial work-up in 22 survival patients (33\%). During follow-up, the precise OHCA diagnosis in this population was: ischemic cardiomyopathy (without acute coronary lesion during OHCA) in 6 patients, right arrhythmogenic dysplasia in 3 patients, hypertrophic cardiomyopathy in 2 patients, coronary spasm in 1 patient, dilated cardiomyopathy in 1 patient, and idiopathic in 9 patients.

No difference was found between survival and non-survival patients regarding the cause of OHCA and the repolarization pattern.

After a mean follow-up of $8 \pm 9$ months, early repolarization pattern was diagnosed in $7 \%$ of patients with pattern $1,13 \%$ with pattern $2,60 \%$ with pattern 3 and $88 \%$ with pattern 4 (Figure 3). Concerning the 9 surviving patients without etiology during follow-up, 4 patients had a type 4 pattern at the initial presentation and the same 4 patients displayed ERep during follow-up.

Figure 4 shows examples of ECG after long-term follow-up for survival patients with patterns 3 and 4 immediately after OHCA.

\section{DISCUSSION}

Our study demonstrated that immediate repolarization abnormalities following OHCA were associated with specific causes of cardiac arrest: isolated ST segment elevation was associated with acute coronary disease, whereas the presence of ERep was a marker of a non-ischemic event. In the vast majority of patients displaying an ERep pattern at initial presentation, no etiology could be found for cardiac arrest during follow-up. Finally among surviving patients, this pattern if present immediately after OHCA, even though less pronounced, persisted after long term follow-up in most of the patients. 
Electrocardiographic ST-segment abnormalities are common after cardiac arrest resuscitation. These repolarization abnormalities can be transient and non-specific (15). Indeed, these ECG modifications could be caused by electrical cardioversion, electrolyte abnormalities or hypothermia secondary to cardiac arrest (16). However, specific causes of OHCA such as acute coronary ischemia $(5,6)$ or early repolarization could also modify the interpretation of repolarization abnormalities following resuscitation (7). Indeed numerous studies have found an excellent correlation between isolated ST segment elevation immediately after OHCA and the presence of acute coronary disease explaining the $\mathrm{OHCA}(5,6)$. Consistent with these data, we demonstrated that an isolated ST segment elevation was strongly associated with acute coronary disease, with a positive predictive value of $79 \%$. Thus, we recommend that patients with ST segment elevation immediately after OHCA should go immediately to the cardiac catheterization laboratory for coronary angiogram.

Numerous publications have highlighted the benign nature of ERep $(17,18)$. However, recent studies are challenging these findings and indicate that ERep is associated with an increased risk of sudden cardiac death $(7,8)$. In accordance with this, experimental studies showed that early ERep ECG pattern was secondary to a form of transmural electrical heterogeneity, increasing the risk of malignant arrhythmias (19).

Our study showed that isolated ERep was present in 9\% of patients after OHCA. As in Brugada syndrome (20), ERep abnormalities are temporally dynamic and some circumstances such as hypothermia could increase this phenomenon (7). One explanation for this high prevalence of ERep could be that as it increases before the 
onset of malignant arrhythmia, it is also possible that it could increase immediately after the occurrence of cardiac arrest. This hypothesis is confirmed by some observational data collected in our study (Figure 5). Additionally, these patients were mainly diagnosed as having a non-ischemic cardiac arrest (80\%).

Eight per cent of our population exhibited ERep associated with ST segment elevation (pattern 3 ). In this specific subgroup, $47 \%$ of patients were found to have a non-ischemic cardiac arrest. The explanation for the association of these two repolarization abnormalities in patients with or without acute coronary lesion is unclear. However, it has been demonstrated experimentally that the pathophysiology of ST segment elevation and the genesis of ERep are similar $(21,22)$. Moreover, consistent with our data, Haissaguerre et al described a dramatic increase in ERep before the onset of malignant arrhythmias, mimicking ST segment elevation during acute myocardial infarction (7) (23). Additionally it has been recently demonstrated that a gene mutation encoding for KATP channels could confer a predisposition to dramatic repolarization changes and ventricular vulnerability in patients with early repolarization (23). However, systematic coronary artery angiography should be recommended in this population as no specific parameter could predict the presence of acute coronary lesion.

Finally, during our long-term follow-up $88 \%$ of survival patients with isolated ERep immediately after OHCA experienced ERep on further stable ECG, highlighting the specificity of this pattern even under acute circumstances.

\section{Study Limitation}

One limitation could be that other factors, such as hypothermia, could have mimicked the presence of ERep immediately after resuscitation. In this case the presence of 
ERep immediately after cardiac resuscitation could have been overestimated however $88 \%$ have this pattern at follow-up at distance in this group of patients. Additionally, other repolarization abnormalities such as ST segment depression or isolated T wave changes were not specifically analyzed in this study to try and predict the presence of coronary disease.

Finally, autopsy was not performed systematically in the non-survival patients. Other causes of death could therefore have been underdiagnosed, leading to an overestimation in the group with an "unknown" cause of death.

\section{CONCLUSION}

In the context of cardiac resuscitation, an ECG with ST elevation favors acute myocardial infarction, whereas the presence of ERep is a marker of a non-ischemic event and future early repolarization syndrome.

\section{REFERENCE}

1. Myerburg RJ, Kessler KM, Casyellanos A: Sudden cardiac death (structure, function and time-dependence of risk). Circulation 1992;85:I2-I10.

2. Zipes DP, Wellens HJJ: Sudden cardiac death. Circulation 1998;98:2334-2351.

3. Atwood C, Eisenberg MS, Herlitz J, Rea TD: Incidence of EMS treated out-of-hospital cardiac arrest in Europe. Resuscitation 2005;67:75-80.

4. Huikuri HV, Castellanos A, Myerburg RJ: Sudden death due to cardiac arrhythmias. N Engl J Med 2001;345:1473-1482.

5. Anyfantakis ZA, Baron G, Aubry P, Himbert D, Feldman LJ, Juliard JM, RicardHibon A, Burnod A, Cokkinos DV, Steg PG: Acute coronary angiographic findings in survivors of out-of-hospital cardiac arrest. Am Heart J 2009;157:312-318.

6. Spaulding CM, Joly LM, Rosenberg A, Monchi M, Weber SN, Dhainaut JF, Carli P: Immediate coronary angiography in survivors of out-of-hospital cardiac arrest. N Engl J Med 1997;336:1629-1633. 
7. Haïssaguerre M, Derval N, Sacher F, Jesel L, Deisenhofer I, de Roy L, Pasquié JL, Nogami A, Babuty D, Yli-Mayry S, De Chillou C, Scanu P, Mabo P, Matsuo S, Probst V, Le Scouarnec S, Defaye P, Schlaepfer J, Rostock T, Lacroix D, Lamaison D, Lavergne T, Aizawa Y, Englund A, Anselme F, O'Neill M, Hocini M, Lim KT, Knecht S, Veenhuyzen GD, Bordachar P, Chauvin M, Jais P, Coureau G, Chene G, Klein GJ, Clémenty J: Sudden cardiac arrest associated with early repolarization. N Engl J Med 2008;358:2016-2023.

8. Rosso R, Kogan E, Belhassen B, Rozovski U, Scheinman MM, Zeltser D, Halkin A, Steinvil A, Heller K, Glikson M, Katz A, Viskin S: J-point elevation in survivors of primary ventricular fibrillation and matched control subjects: incidence and clinical significance. J Am Coll Cardiol 2008;52:1231-1238.

9. Klatsky AL, Oehm R, Cooper RA, Udalstova N, Armstrong MA: The early repolarization normal variant electrocardiogram: correlates and consequences. Am J Med 2003;115:171-177.

10. Mehta M, Jain AC, Mehta A: Early repolarization. Clin Cardiol 1999;22:59-65.

11. Brugada J, Brugada R, Brugada P: Right bundle-branch block and ST-segment elevation in leads V1 through V3: a marker for sudden death in patients without demonstrable structural heart disease. Circulation 1998;97:457-460.

12. GUSTO Investigators: An international randomized trial comparing four thrombolytic strategies for acute myocardial infarction. N Engl J Med 1993;329:673682.

13. Brain Resuscitation Clinical Trial II Study Group: A randomized clinical study of a calcium-entry blocker (lidoflazine) in the treatment of comatose survivors of cardiac arrest. N Engl J Med 1991;324:1225-1231.

14. Lemiale V, Huet O, Vigué B, Mathonnet A, Spaulding C, Mira JP, Carli P, Duranteau J, Cariou A: Changes in cerebral blood flow and oxygen extraction during post-resuscitation syndrome. Resuscitation 2008;76:17-24.

15. Chatterjee K, Harris A, Davies G, Leatham A: Electrocardiographic changes subsequent to artificial ventricular depolarization. Br Heart J 1969;31:770-779.

16. Wang K, Asinger RW, Marriott HJ: ST-segment elevation in conditions other than acute myocardial infarction. N Engl J Med 2003;349:2128-2135.

17. Brady WJ, Chan TC: Electrocardiographic manifestations: benign early repolarization. J Emerg Med 1999;17:473-478.

18. Klatsky AL, Oehm R, Cooper RA, Udaltsova N, Armstrong MA: The early repolarization normal variant electrocardiogram: correlates and consequences. Am J Med 2003;115:171-177. 
19. Gussak I, Antzelevitch C: Early repolarization syndrome: clinical characteristics and possible cellular and ionic mechanisms. J Electrocardiol 2000;33:299-309.

20. Probst V, Denjoy I, Meregalli PG, Amirault JC, Sacher F, Mansourati J, Babuty D, Villain E, Victor J, Schott JJ, Lupoglazoff JM, Mabo P, Veltmann C, Jesel L, Chevalier $\mathrm{P}$, Clur SA, Haissaguerre M, Wolpert C, Le Marec H, Wilde AA: Clinical aspects and prognosis of Brugada syndrome in children. Circulation 2007;115:2042-2048.

21. Shinde R, Shinde S, Makhale C, Grant P, Sathe S, Durairaj M, Lokhandwala Y, Di Diego J, Antzelevitch C: Occurrence of "J waves" in 12-lead ECG as a marker of acute ischemia and their cellular basis. Pacing Clin Electrophysiol 2007;30:817-819.

22. Yan GX, Antzelevitch C: Cellular basis for the electrocardiographic $\mathrm{J}$ wave.

Circulation 1996;93:372-379.

23. Haïssaguerre $M$, Chatel $S$, Sacher $F$, Weerasooriya R, Probst $V$, Loussouarn $G$, Horlitz M, Liersch R, Schulze-Bahr E, Wilde A, Kääb S, Koster J, Rudy Y, Le Marec H, Schott JJ : Ventricular fibrillation with prominent early repolarization associated with a rare variant of KCNJ8/KATP channel. J Cardivasc Electrophysiol 2009;20:93-98.

\section{FIGURE LEGENDS}

Figure 1: Diagnostic strategy for each patient following successful cardiopulmonary resuscitation. $\mathrm{CT}=$ Computed Tomography.

Figure 2: Typical ECG examples of pattern 2, 3 and 4 immediately after cardiac resuscitation.

Pattern 2: isolated ST segment elevation (black arrow)

Pattern 3: ERep with a notch aspect (black circle) in lead V4 and a slurred aspect in lead V5 and ST segment elevation (black arrow). Note the different shape in ST segment elevation between pattern 2 and 3

Pattern 4: Isolated ERep (slurred in this example) (black arrow) 
Figure 3: Percentage of ERep diagnosed during long-term follow-up according to their initial repolarization pattern in survival patients. ERep: Early repolarization; ECG: electrocardiogram.

Figure 4: Example of ECG in survival patients during long-term follow-up.

A. ECG of Pattern 3 patient 3 months after cardiac resuscitation showing a typical ERep (slurred and notch) (black arrow). Patient with normal coronary angiogram. B. ECG of Pattern 4 patient 3 months after cardiac resuscitation showing a typical ERep (slurred) (black arrow). Patient with normal coronary angiogram.

Figure 5: Example of ECG immediately after cardiac resuscitation. Patient with pattern 3 on immediate ECG following cardiac arrest associated with ventricular arrhythmia. The black circle highlights the presence of a notch aspect at the end of the ventricular depolarization. Patient with normal coronary angiogram. 